\title{
Qualitative Research: Ethical Issues
}

\author{
${ }^{1}$ Uttam Kumar Paul, ${ }^{2}$ Arup Bandyopadhyay
}

\section{ABSTRACT}

Background: Ethical principles are part and parcel of the qualitative research and become an integral of qualitative research beginning from the framing of the research questions, formation of the research design, selecting the proper methodology, selection of subjects in the population to be studied, data collection, data analysis and forming an inference.

Ethical principles: The four basic principles of medical ethics are beneficence, non-maleficence, autonomy, and justice. Other important principles of ethics are confidentiality, fidelity, veracity (truthfulness) and accountability. A very important step of research ethics is informed consent. The purpose is to let the participant know the details of the research work-its purpose, principle, and methods. The informed consent form should be in the vernacular language, explained to the patient by or in the presence of a person who he can rely upon, and will be accepted by the court of law. The other important factors of ethics are reciprocity, power and empowerment, ownership and Hazards, risk and compensation.

Institutional ethical committee: The institutional ethical committee also considers some aspects of research ethics. These are validity, reliability, transferability, confirmability, and triangulations.

Conclusion: The most important aspects of ethics in qualitative research are: becoming highly careful in delicate issues, truthfulness, honesty, and integrity

Keywords: Ethical issues, Research, Qualitative.

How to cite this article: Paul UK, Bandyopadhyay A, Qualitative Research: Ethical Issues. Bengal Physician Journal 2018; 5(3):45-47.

\section{Source of support: Nil}

Conflict of interest: None

\section{INTRODUCTION}

Ethical issues are now prime concerns in medical research particularly those involving human subjects. However, a common notion is that ethical issues are not that important in qualitative types of medical research. But this notion is entirely debatable. The fact is that for any

${ }^{1}$ Professor, ${ }^{2}$ Professor and Head

${ }^{1}$ Department of Medicine, MGM Medical College, Kisanganj, Bihar, India

${ }^{2}$ Department of Physiology, Agartala Government Medical College, Tripura, India

Corresponding Author: Uttam Kumar Paul, Professor, Department of Medicine, MGM Medical College, Kishanganj, Bihar, India, e-mail : druttam131065@gmail.com medical research on human subjects, ethics is of utmost importance.

Regarding ethics, there can never be a cut off division between qualitative and quantitative differences.

On the contrary, specific qualitative research methodologies like phenomenology and ethnography do pose complex ethical challenges and thus beget close scrutiny on ethical issues. Any revolutionary medical research becomes path-breaking only when it is based on solid pillars of truthfulness, honesty, and integrity which together form the backbone of the ethical considerations of any form whatsoever. ${ }^{1}$

Ethics does not only become relevant in certain strata of qualitative of but it pervades the length and breadth of any researches particularly when it is a form of "action research "where the research process must be followed by actions to get the full benefit of the research and to make it purposeful for the society. Ethics becomes an integral of qualitative research beginning from the framing of the research questions, formation of the research design, selecting the proper methodology, selection of subjects in the population to be studied, data collection, data analysis and forming an inference.

Ethical principles are part and parcel of the whole of the qualitative research project, and then only the study can assure quality, rigor, generalizability, validity, reliability dependability and credibility. It is the only thing which can protect the interests of the participants and save them from any impending harm.

\section{FUNDAMENTAL PRINCIPLES OF ETHICS}

Tom Beauchamp and James Childress in their classic book "Principles of Biomedical ethics" Oxford (1994) first recognized the four basic principles of medical ethics, ${ }^{2}$ viz.:

1. Beneficence (Salus aegroti suprema lex): The researcher should work for the best interest of the patient, the scientific community, a population and/or the society as a whole.

2. Non-maleficence (premium non-nocere): This means first not harm.

3. Autonomy (voluntas aegrot isuprema lex): The patient has the right to join or not to join any research project.

O A study was done on "household torture on elderly women." Interviews were done on other household member's domestic workers and neighbors. But, the tortured elderly ladies themselves were 
spared lest an interview should cause acute emotional trouble in them. But, their opinions could have been taken whether they wanted to join or not. That is, their autonomy was hampered. ${ }^{3}$

o They should also have the liberty to leave at any moment even when the interview is going on.

o No retaliating measures should ever be taken for their non-participation. There should be no direct or indirect threatening that their treatment would be hampered if they do not participate.

O Again, no enticement should be placed before them; rather we should appeal to their higher consciences.

4. Justice (Justicia): Fair and spontaneous distribution of all health resources and services, equally to all patients, whether he co-operates with your study project or not, especially regarding scarce health resources.

The other principles of ethics are:

- Confidentiality: The term "confidentiality" means that what so ever information the doctor (or the researcher, for that matter) might have received during the course of his studies through interview or observation regarding the confidential aspects of any participant must be kept strictly secret, and must not be revealed or leaked even in the least.

- Fidelity: Loyalty and promise to fulfill all commitments.

- Veracity: Implies truthfulness. Veracity is an important component of building a trustworthy relationship.

- Accountability: Individuals need to be responsible for their actions.

- A signed declaration in this regard, over and above the verbal assurances, should also be given to the patient/participant at the beginning of the project work. In the USA in 1996 an act was promulgated named The Health Insurance Portability and Accountability Act (HIPAA) in which this privacy or confidentiality was the foremost issue. ${ }^{4}$ The main purpose of this act was to protect the personal information of the patient/participant. In the present electronic era, all patient related information stored digitally must be irrevocably locked, so that no one can view even the minimum without the researcher's permission. Just as a researcher is legally protected not to reveal any information even in the court of law, so also, the participant has the right to sue against the researcher if there is any evidence of disclosure of any unwanted or secret information, with proper evidence and within 180 days of the time of interview. However, critics like Jacol Appel have also questioned the validity of many of the issues on confidentiality. For example, a doctor knowing a recent gun-shot injury to a patient should report to the police, reveal- ing the proper stakeholder about a person's illicit or extramarital relationship may not be normally right, but when one partner is suffering from HIV infection, the same should be revealed to the other partner to prevent transverse and/or vertical propagation of the disease. Parental notification of under-age abortion is also ethically acceptable. So, the recent trend is to accept a nuanced or balanced approach to this duty of confidentiality acknowledging the need for flexibility in suitable cases.

\section{INFORMED CONSENT}

A critical step which is both concrete and conspicuous while dealing with research ethics is informed consent. There is an "informed consent form" or proforma, as well as a participant's information sheet. The purpose is to let the participant know the details of the research work-its purpose, principle, and methods. Then the participant in his free mind will sign for giving consent to be a participant if the project work is according to his values and wishes. There should neither be any coercion or enticement in the whole process. There appears no problem if the researcher is transparent and the participants are knowledgeable and in a clear mind. But the problem arises when the researcher tries to conceal something or in a hurry, does not pay proper importance to the process or the participant is not so educated, mature, sane or not is a healthy mental state. In those cases, some precautionary steps have to be taken, like, the informed consent form should be in the vernacular language, explained to the patient by or in the presence of a person who he can rely upon, and will be accepted by the court of law. It is extremely important in vulnerable populations, like children, psychiatric patients, etc. where the informed consent should be sought and signed by the parents, legal guardians, next of any kind of socially and/or legally acceptable guardians.

\section{OTHER ETHICAL FACTORS}

The other factors include:

- Reciprocity: This means that the doctors and researchers should reciprocate courtesy to a participant of their research work in lieu of his co-operation and good gesture as a participant. This should, however, not be confused with enticement.

- Power and empowerment: The patients should be empowered to reveal anything not asked for, but they deem it relevant and necessary; they can also conceal something they don't want to reveal.

- Ownership: The patients should be made to feel that the project is for their benefit and population like him. Thus they should be made to feel an ownership of the 
project. They should be given the freedom to suggest any changes in the project work.

- Hazards, risks, and compensation: Even if it is qualitative research yet there could as well be hazards and risks, and the questions of compensation come along with them. The patients and/or their legal guardians should be made aware of the hazards, risks, and corresponding compensations before beginning the project.

\section{ETHICAL CONSIDERATIONS OF INSTITUTIONAL ETHICAL COMMITTEE (IEC)}

One important and common problem in qualitative medical research is that the IEC members are often considerably ignorant about the specialties and uniqueness of this type of medical research and hence often cancels projects on dubious points, simply due to their own lack of awareness. ${ }^{5}$

The institutional ethical committee also considers some aspects of research ethics. These should be kept in mind by all researchers before the beginning of the research project. These are:

- Validity: Means how accurate a tool is to measure what it is supposed to measure.

- Reliability: Means consistency; that is, if the research is done in a different location at another time, by different investigations, will the result be more or less the same?

- Transferability: This is the same as "generalizability." It means the findings can be extrapolated in other contexts, times, populations and situations.

- Confirmability: Means the documents are such that if there is an audit during or after the research (internal or external audit), the data can be verified from the documents (e.g., audio, video, photographs, written statements, and journals).

- Triangulations: Means interaction among multiple sources of data, methods, investigations and expert opinions. One of the different types of triangulation is "theoretical triangulations" in which several experts or relevant persons judge the theoretical aspects of the research project and boil down to a common issue.

\section{DELICATE ISSUES}

Extreme care and caution are needed while dealing with delicate issues. In authors' experience, a highly difficult situation accrued while taking interviews of spouses of urethral stricture patients regarding their problems and feelings at a stricture level. Such situations can also occur while taking interviews with dangerously debilitating rare diseases, terminal patients of cancer, etc., at their deathbeds, rape victims, psychiatric diseases, mothers of children with moribund diseases and so on. The cautions include taking an experienced and expert lady for an interview, who knows the language and culture of the interviewee, taking written permission from stakeholders, and government authorities and using a video-recording. ${ }^{6}$

\section{CONCLUSION}

The most important aspects of ethics in qualitative research are becoming highly careful in delicate issues, truthfulness, honesty, and integrity. A critical problem of qualitative research is ignorance of the specificity of the same by one or more members of the IEC when they insist on or even reject the proposal on dubious issues which are essential components of quantitative research but not in qualitative ones.

\section{REFERENCE}

1. Orb A, EisenhavenL, Wynaden D. Ethics in qualitative research. J of Nursing Scholarship. 2001; 33(1):93-96.

2. Dresser R. Time for new ruler on human subject's research? Hastings center Report 1998;28(6):23-24.

3. Randonis BM. Ethical considerations in qualitative research with hospice patients. Qualitative Health Research 1992;2(2): 238-249.

4. Halai A. Ethics in qualitative research: issues and challengers. Equal working paper no. 4 (2006). The Aga Khan University, Pakistan.

5. Dongre AR, Sankaran R. Ethical issues in qualitative research: challenges and options. IntJ of Medis and public health (2015).5(6): 1187-1194.

6. Pramanik S, Pal DK, et al. A qualitative study on the perceptions of patients with urethral stricture. Int Surg J 2017;4: 4043-4048. 